\title{
Utilização do farelo de soja centrifugado visando à produção do superprecoce
}

\author{
Utilization of centrifugeted soybean meal for feeding of calves in feedlot
}

\author{
Mikael Neumann $^{1}$ João Restle ${ }^{2}$ Alexandre Nunes Motta de Souza ${ }^{3}$ \\ Ivan Luis Brondani ${ }^{4}$
}

\section{RESUMO}

Este experimento teve por objetivo avaliar a utilização do farelo de soja centrifugado (FSC) como substituto ao farelo de soja (FS) na fração concentrada da dieta de bezerros de corte em confinamento, sendo testados os seguintes tratamentos: $T_{1}-100 \%$ de FS; $T_{2}-66 \%$ de FS + 34\% de FSC; $T_{3}-34 \%$ de FS + 66\% de FSC; e $T_{4}-100 \%$ de FSC. Foram utilizados 36 bezerros machos da raça Braford, com idade média de sete meses e peso vivo médio inicial de $202 \mathrm{~kg}$. O confinamento compreendeu 168 dias de avaliação, sendo dividido em quatro períodos de 42 dias cada. A relação volumoso:concentrado foi de 60:40 para o $1^{\circ}$ e 2o períodos, de 50:50 para o 3o período e de 45:55 para o 4o período. Não houve interação $(P>0,05)$ entre nível de substituição da fonte protéica e período de avaliação em confinamento para os parâmetros relativos aos consumos diários de matéria seca (CMS), proteína bruta (CPB) e energia digestível (CED), respectivamente, expressos em kg animal ${ }^{-1}$ (CMSD e CPBD) ou Mcal/animal (CEDD), por $100 \mathrm{~kg}$ de peso vivo (CMSP, CPBP e CEDP) e por unidade de tamanho metabólico (CMSM, CPBM e CEDM), ao ganho de peso médio diário (GMD) e a eficiência da transformação da matéria seca consumida (CA) e da proteína bruta consumida (EPB) em ganho de peso. A utilização de farelo de soja centrifugado como fonte protéica em substituição parcial ou integral ao farelo de soja na fração concentrada da dieta alimentar de bezerros de corte, visando à produção do superprecoce, não comprometeu $(P>0,05)$ o consumo de alimentos, o ganho de peso médio diário e a eficiência da transformação da matéria seca consumida e da proteína bruta consumida em ganho de peso.

Palavras-chave: Braford, confinamento, proteína bruta, substituição.

\section{ABSTRACT}

The experiment was conducted with the objective to evaluate the use of soybean meal centrifugeted (SMC) as substitution for soybean meal (SM) in the concentrate fraction of the diet of confined steer calves, being tested the following treatments: $T_{1}-100 \%$ of SM; $T_{2}-66 \%$ of $S M+34 \%$ of $S M C$; $T_{3}-34 \%$ of $S M+66 \%$ of SMC e $T_{4}-100 \%$ of SMC. Thirty-six steers no castrated Braford (5/8 Hereford 3/8 Nellore) calves with an age average of seven months and average live weight of $202 \mathrm{~kg}$, were used. The whole feedlot period was 168 days, divided in four periods of 42 days. The roughage:concentrate ratio was 60:40 for the first and second periods, 50:50 for the third period and 45:55 for the fourth period. No signification interaction was observed between substitution of level of the protein source and feedlot evaluation period for average daily dry matter intake (DMI), crude protein intake (CPI) and digestible energy intake (DEI), respectively, expressed per animal (DMID, CPID and DEID), per $100 \mathrm{~kg}$ of live weight (DMIP, $C P I P, D E I P)$ and per unit of metabolic weight (DMIM, CPIM and DEIM), for average daily weight gain (ADG), feed conversion (FC) and crude protein efficiency (CPE). The use of soybean meal centrifugeted with protein source as substitution partial or total of soybean meal in concentrate fraction of the diet feedlot steer calves, for young beef cattle production, did not affect $(P>.05)$ of average dry matter intake, daily weight gain, feed conversion and crude protein efficiency.

Key words: Braford, crude protein, feedlot, substitution.

\section{INTRODUÇÃO}

A prática do confinamento tem permitido ao produtor abater bovinos jovens na entressafra, permitindo maior rentabilidade da atividade, além de favorecer outras categorias de animais com a liberação de áreas forrageiras (RESTLE et al., 1999a). Porém, a terminação de animais superprecoces somente é possível e viável com a utilização de dietas alimentares

${ }^{1}$ Curso de Medicina Veterinária , Universidade Estadual do Centro-Oeste (UNICENTRO-PR), Guarapuava, PR, Brasil. E - mail: mikaelneumann@hotmail.com. Autor para correspondência.

${ }^{2}$ Escola de Veterinária, Universidade Federal de Góias, Goiânia, GO, Brasil. E-mail:jorestle@terra.com.br

${ }^{3}$ Programa de Pós-graduação em Zootecnia, Universidade Federal do Rio Grande do Sul (UFRGS), Porto Alegre, RS, Brasil.

E-mail: mottadesouza@terra.com.br

${ }^{4}$ Departamento de Zootecnia da Universidade Federal de Santa Maria (UFSM). Santa Maria, RS, Brasil. E - mail: brondani@ccr.ufsm.br 
equilibradas, através do uso de volumosos de alta qualidade associados ao uso de concentrado. Segundo RESTLE et al. (1999b), dentre os alimentos concentrados, os protéicos, apresentam o maior custo. BRITO et al. (1997) e RESTLE et al. (2000) ressaltam que o custo da alimentação de bovinos representa em média $70 \%$ do custo total do confinamento, e que a escolha dos ingredientes da dieta alimentar, principalmente as fontes protéicas, merecem atenção especial, visando melhor desempenho animal e redução do custo de produção.

O uso do farelo de soja, como fonte protéica, na fração concentrada da dieta alimentar de bovinos de corte em confinamento tem aumentado sensivelmente os custos de alimentação, devido aos altos preços praticados em nível de mercado. Desta forma, pesquisas têm sido conduzidas (PASCOAL et al., 2000; PELEGRINI et al., 2000) visando estudar alternativas de substituição do farelo de soja por outros alimentos protéicos. O Sul do Brasil possui poucas opções de alimentos substitutivos ao farelo de soja, que é o concentrado protéico mais usado na formulação de rações. O farelo centrifugado de soja é um subproduto do farelo de soja, obtido por processos químicos, em que uma fração importante da proteína é extraída para confecção de produtos alimentícios para consumo humano, constituindo-se em uma alternativa de alto potencial à substituição do farelo de soja na dieta alimentar de bovinos de corte, apesar deste material residual desidratado apresentar menor valor nutritivo, com valores médios de 33\% de proteína bruta e $71 \%$ de nutrientes digestíveis totais em relação ao farelo de soja.

O objetivo deste trabalho foi avaliar o potencial de utilização do farelo de soja centrifugado como substituto parcial ou total do farelo de soja na fração concentrada da dieta de bezerros de corte, através do seu desempenho em confinamento.

\section{MATERIAL E MÉTODOS}

O experimento foi conduzido no Departamento de Zootecnia da UFSM, localizada fisiograficamente na Depressão Central do Estado do Rio Grande do Sul, a uma altitude de $95 \mathrm{~m}$. Cartograficamente, se localiza a $29^{\circ} 43^{\prime}$ de latitude Sul e $53^{\circ} 42^{\prime}$ de longitude Oeste.

Os tratamentos constaram de dietas alimentares com quatro níveis de substituição do farelo de soja (FS), pelo farelo centrifugado de soja (FCS): $\mathrm{T}_{1}$ - 100\% de FS; $\mathrm{T}_{2}-66 \%$ de FS + 34\% de FSC; $\mathrm{T}_{3}-34 \%$ de FS + 66\% de FSC; e $\mathrm{T}_{4}-100 \%$ de FSC.

Foram utilizados 36 bezerros da raça Braford (5/8 Hereford 3/8 Nelore), machos inteiros, oriundos do mesmo rebanho, com idade média de sete meses e peso vivo médio inicial de 202kg. A partir dos 210 dias de idade, os bezerros foram distribuídos em oito boxes de confinamento com quatro ou cinco animais, equilibrados por peso corporal e escore de condição corporal. Foram inicialmente submetidos a um período de 30 dias de adaptação às instalações e ao sistema de manejo da dieta alimentar, tendo sido realizada a aplicação de um vermífugo de amplo espectro.

A alimentação controlada e a avaliação do desempenho e consumo de alimentos dos animais compreendeu um período total de 168 dias, sub-dividido em quatro períodos de 42 dias. A composição da dieta alimentar é apresentada na tabela 1 . Como volumoso, utilizou-se a mistura de silagens de milho e sorgo, na relação 50:50, ensilados com teores médios de MS de $27 \%$. A relação volumoso:concentrado da dieta alimentar foi de 60:40 para a adaptação dos animais e

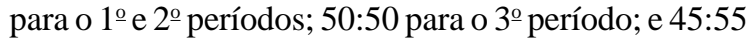
para o $4^{\circ}$ período.

O sistema de alimentação foi "ad libitum” duas vezes ao dia, a primeira pela manhã às 08 horas e a segunda às 16 horas. $\mathrm{O}$ ajuste do fornecimento da quantidade de alimento "in natura" foi calculado diariamente, considerando uma sobra de 7\% da matéria seca oferecida em relação à consumida. $\mathrm{O}$ consumo voluntário dos alimentos foi registrado diariamente através da pesagem da quantidade oferecida e das sobras do dia anterior. A dieta alimentar foi balanceada com teores de proteína bruta e concentração de energia digestível, respectivamente, de $15,6 \%$ e 3,101Mcal $\mathrm{kg}^{-1}$ de MS para o primeiro e segundo períodos de confinamento; de 12,1\% e 3,144Mcal kg $^{-1}$ de MS para o $^{-1}$ terceiro período; e de $10,2 \%$ e $3,180 \mathrm{Mcal} \mathrm{kg}^{-1}$ de MS para o quarto período, conforme NRC (1984) para a categoria animal utilizada, objetivando um ganho de peso de $1,2 \mathrm{~kg}$ animal ${ }^{-1} \mathrm{dia}^{-1}$.

As instalações do confinamento foram do tipo semi-coberto, equipados com bebedouro com bóia automática e comedouros de madeira. No final do período de adaptação e do período experimental, os animais foram pesados, sempre pela parte da manhã e após um jejum de sólidos de 12 horas, com pesagens intermediárias correspondentes a cada período de avaliação.

Foram coletadas amostras representativas dos componentes da dieta alimentar no início da adaptação e a cada período de avaliação do experimento. Estas amostras foram pré secadas em estufa de ar forçado a $55^{\circ} \mathrm{C}$ por 72 horas para determinação do teor de matéria seca, sendo seqüencialmente moídas em moinho tipo "Wiley“ com peneira de malha de um milímetro. Posteriormente, nas 
Tabela 1 - Composição percentual das dietas alimentares experimentais, conforme período de avaliação do confinamento.

\begin{tabular}{|c|c|c|c|c|}
\hline \multirow[t]{2}{*}{ Constituintes } & \multicolumn{4}{|c|}{ Níveis de substituição } \\
\hline & $100 \% \mathrm{FS}$ & $66 \% \mathrm{FS}$ & $34 \% \mathrm{FS}$ & $0 \% \mathrm{FS}$ \\
\hline $1^{\circ}$ e $2^{\circ}$ Períodos & \multicolumn{4}{|c|}{$\%$} \\
\hline Silagem de milho + sorgo (50:50) & 60 & 60 & 60 & 60 \\
\hline Farelo de soja & 20,62 & 15,47 & 8,99 & 0,00 \\
\hline Farelo de soja centrifugado & 0,00 & 7,94 & 17,78 & 33,08 \\
\hline Grão de milho & 18,18 & 18,39 & 12,03 & 5,72 \\
\hline Calcário Calcítico & 0,40 & 0,40 & 0,40 & 0,40 \\
\hline Fosfato bicálcico & 0,40 & 0,40 & 0,40 & 0,40 \\
\hline Sal comum & 0,40 & 0,40 & 0,40 & 0,40 \\
\hline Total & 100,00 & 100,00 & 100,00 & 100,00 \\
\hline \multicolumn{5}{|l|}{$3^{\circ}$ Período } \\
\hline Silagem de milho + sorgo (50:50) & 50 & 50 & 50 & 50 \\
\hline Farelo de soja & 10,29 & 7,89 & 4,66 & 0,00 \\
\hline Farelo de soja centrifugado & 0,00 & 3,96 & 9,31 & 17,00 \\
\hline Grão de sorgo & 38,21 & 36,65 & 34,53 & 31,50 \\
\hline Calcário calcítico & 1,00 & 1,00 & 1,00 & 1,00 \\
\hline Sal comum & 0,50 & 0,50 & 0,50 & 0,50 \\
\hline Total & 100,00 & 100,00 & 100,00 & 100,00 \\
\hline \multicolumn{5}{|l|}{$4^{\circ}$ Período } \\
\hline Silagem de milho + sorgo (50:50) & 45 & 45 & 45 & 45 \\
\hline Farelo de soja & 5,34 & 4,09 & 2,42 & 0,00 \\
\hline Farelo de soja centrifugado & 0,00 & 2,05 & 4,84 & 8,79 \\
\hline Grão de sorgo & 48,01 & 47,21 & 46,09 & 44,56 \\
\hline Calcário calcítico & 1,10 & 1,10 & 1,10 & 1,10 \\
\hline Sal comum & 0,55 & 0,55 & 0,55 & 0,55 \\
\hline Total & 100,00 & 100,00 & 100,00 & 100,00 \\
\hline
\end{tabular}

amostras de cada alimento, foram determinados os teores de matéria seca total (MS), de matéria mineral (MM) e de proteína bruta (PB), conforme AOAC (1984); e a digestibilidade "in vitro" da matéria orgânica (DIVMO) (TILLEY \& TERRY, 1963). Os teores de fibra em detergente neutro (FDN) foram determinados pelo método descrito por VAN SOEST \& WINE (1967). Para o cálculo de energia digestível (ED), utilizaram-se as equações descritas pelo ARC (1980), com base na DIVMO e matéria orgânica (MO).

Os parâmetros estimados foram os consumos médios diários de matéria seca (CMS) e de proteína bruta (CPB), respectivamente, expressos em $\mathrm{kg} / \mathrm{animal}$ (CMSD e CPBD), por 100kg de peso vivo (CMSP e CPBP) e por unidade de tamanho metabólico (CMSM e CPBM), bem como os consumos médios diários de energia digestível (CED), expressos em Mcal/ animal (CEDD), por 100kg de peso vivo (CEDP) e por unidade de tamanho metabólico (CEDM), o ganho de peso médio diário (GMD), a conversão alimentar (CA) e a eficiência de transformação da proteína bruta consumida (EPB) em ganho de peso.

O delineamento experimental foi o inteiramente casualizado, composto por quatro tratamentos (níveis de substituição), com duas repetições. Cada unidade experimental foi composta por um lote de quatro ou cinco animais. Os dados coletados de cada parâmetro foram submetidos à análise de variância através do pacote estatístico SAS (1993) e as diferenças entre as médias foram analisadas pelo teste Tukey ao nível de significância de 5\%. O modelo estatístico utilizado foi o seguinte: $\mathrm{Y}_{\mathrm{ijk}}=\mathrm{m}+\mathrm{NS}_{\mathrm{i}}+$ $\mathrm{R}_{\mathrm{j}}(\mathrm{NS})_{\mathrm{i}}+\mathrm{P}_{\mathrm{k}}+(\mathrm{NS} * \mathrm{P})_{\mathrm{ik}}+\mathrm{E}_{\mathrm{ijk}}$ onde: $\mathrm{Y}_{\mathrm{ijk}}=$ variáveis dependentes; $m$ = média das observações; $\mathrm{NS}_{\mathrm{i}}=$ efeito do nível de substituição de ordem “i”, sendo 1 (nível 100\% FS), 2 (nível 66\% FS), 3 (nível 34\% FS) e 4 (nível $0 \%$ FS); R (NS) = efeito aleatório baseado na repetição dentro do ${ }^{\mathrm{j}}$ tratamento (NS) (Erro a); $\mathrm{P}_{\mathrm{k}}=$ efeito do período de avaliação de ordèm “j”, sendo 1 ( $1^{\underline{o}}$ período), 2 ( $2^{\circ}$ período), 3 ( $3^{\circ}$ período) e 4 ( $4^{\circ}$ período); $\left(N S^{*} \mathrm{P}\right)_{\mathrm{ik}}=$ efeito da interação entre o tratamento nível de substituição de ordem "i” e período de avaliação de ordem " $\mathrm{k}$ ”; e $\mathrm{E}_{\mathrm{ijk}}=$ erro aleatório residual, assumindo distribuição normal média igual a zero e variância $\sigma^{2}$ (Errob).

Os dados também foram submetidos à análise de regressão polinomial, considerando a variável período de confinamento (dias), pelo procedimento “proc reg” do programa SAS (1993).

Ciência Rural, v.36, n.2, mar -abr, 2006. 


\section{RESULTADOS E DISCUSSÃO}

Na tabela 2, constam os resultados da análise bromatológica dos alimentos utilizados nas dietas dos animais em confinamento. $\mathrm{O}$ farelo de soja (FS) apresentou maior valor protéico (48,0 contra $32,0 \%)$ e menor concentração de FDN (16,93 contra 35,95\%) frente ao farelo de soja centrifugado (FSC). O processo químico de extração da fração protéica mostrou que a DIVMO do farelo de soja (90,59\%) manteve-se constante frente a forma centrifugada (90,21\%). A disponibilidade atual de oferta para comercialização do FSC no mercado nacional é limitada e regionalizada por depender de atividades ligadas às indústrias alimentícias direcionado ao consumo humano, apesar do intenso crescimento da atividade de cultivo da soja e dos constantes investimentos realizados na indústria de transformação de produtos agrícolas em gêneros alimentícios de maior valor agregado. Já quanto ao custo de aquisição do FSC em relação ao FS, este varia o valor entre 80 a $85 \%$ do custo de aquisição do FS.

Nas tabelas 3 e 4, são apresentados os resultados médios de CMS, CPB e CED, expressos, respectivamente, em $\mathrm{kg} /$ animal (CMSD, CPBD e CEDD), por $100 \mathrm{~kg}$ de peso vivo (CSMP, CPBP e CEDP) e por unidade de peso corporal metabólico (CMSM, CPBM e CEDM), além do GMD, CA, EPB de acordo com o nível de substituição da fonte protéica e período de avaliação. Não houve interação $(P>0,05)$ entre nível de substituição e período de avaliação para os parâmetros avaliados.

Os CMS médios, expressos nas diferentes formas foram similares $(\mathrm{P}>0,05)$ para todos níveis de substituição do FS na dieta alimentar pelo FSC. Resultados superiores em relação aos valores médios observados são relatados por RESTLE et al. (1997) avaliando o desempenho de bezerros Hereford em confinamento num período de 193 dias, com CMSP de 2,64\% e CMSM de $107,6 \mathrm{~g} \mathrm{~kg} \mathrm{~kg}^{-0,75}$ e por RESTLE et al. (1999a) avaliando o desempenho de bezerros Braford em confinamento dos sete aos 12 meses de idade, com CMSP de 2,26\% e CMSM de 124,0g kg ${ }^{-0,75}$.

Os CMS expressos nas diferentes formas foram afetados $(\mathrm{P}<0,05)$ pelo período de avaliação do confinamento. $\mathrm{O}$ consumo de alimentos foi crescente $(\mathrm{P}<0,05)$ frente ao período do confinamento, justificado pelo desenvolvimento corporal dos animais, o que determinou um aumento do CMSD na ordem de 39,21\% do início ao final do confinamento. PASCOAL et al. (2000) verificaram que o aumento da capacidade ingestiva de bezerros de corte, é o principal fator responsável pelos incrementos lineares do CMS frente ao avanço do período de confinamento. A apresentação dos resultados dos CMS, CPB e CED, nas diferentes formas, é importante para verificar possíveis diferenças de comportamento dos animais sob aspectos de palatabilidade e aceitabilidades dos alimentos testados, visto que o desempenho animal é diretamente dependente do nível de consumo diário de nutrientes, e este, por sua vez, é resultado das características químicas, físicas e sensoriais dos alimentos.

Os dados apresentados na tabela 3 mostram que o CMSP foi maior $(\mathrm{P}<0,05)$ no primeiro período (2,31\%) do confinamento diminuindo no segundo período (2,12\%) em 9,48\%, e mantendo-se estável no terceiro $(2,11 \%)$ e quarto $(2,09 \%)$ períodos subsequentes. Quando expresso por unidade de tamanho metabólico, o consumo de alimentos foi similar $(\mathrm{P}>0,05)$ entre os períodos avaliados com valores variando de $88,31 \mathrm{~g} \mathrm{~kg}^{-0,75}$ (segundo período) a 92,55g $\mathrm{kg}^{-0,75}$ (quarto período), mostrando que o aumento da

Tabela 2 - Teores de matéria seca (MS), digestibilidade “in vitro” da matéria orgânica (DIVMO), matéria orgânica (MO), proteína bruta (PB), extrato etéreo (EE), fibra em detergente neutro (FDN) e energia digestível (ED) dos ingredientes das dietas experimentais, com base na matéria seca total.

\begin{tabular}{|c|c|c|c|c|c|c|}
\hline Variável & $\begin{array}{l}\text { Farelo } \\
\text { de soja }\end{array}$ & $\begin{array}{l}\text { Farelo de soja } \\
\text { centrifugado }\end{array}$ & Grãos de milho & Grãos de sorgo & Silagem de milho & Silagem de sorgo \\
\hline & \multicolumn{6}{|c|}{$\%$} \\
\hline MS & 88,90 & 90,34 & 88,90 & 89,98 & 26,45 & 28,03 \\
\hline \multirow[t]{2}{*}{ DIVMO } & 90,59 & 90,21 & 87,20 & 82,26 & 62,03 & 59,25 \\
\hline & \multicolumn{6}{|c|}{$\% \mathrm{MS}$} \\
\hline MO & 94,73 & 95,30 & 99,00 & 99,19 & 96,30 & 95,37 \\
\hline PB & 48,00 & 32,00 & 8,63 & 9,19 & 7,78 & 6,94 \\
\hline $\mathrm{EE}$ & 1,82 & 1,67 & 4,08 & 3,00 & 3,87 & 3,21 \\
\hline \multirow[t]{2}{*}{ FDN } & 16,93 & 35,95 & 13,46 & 16,10 & 56,02 & 57,21 \\
\hline & \multicolumn{6}{|c|}{ Mcal/kg de MS } \\
\hline ED & 3,897 & 3,904 & 3,920 & 3,705 & 2,715 & 2,568 \\
\hline
\end{tabular}


Tabela 3 - Consumo médio diário de matéria seca (CMS) e de proteína bruta (CPB) expresso em kg/animal (CMSD e CPBD), por 100 kg de peso vivo (CMSP e CPBP) e por unidade de peso metabólico (CMSM e CPBM), respectivamente, de bezerros confinados, de acordo com o tratamento e período de avaliação.

\begin{tabular}{|c|c|c|c|c|c|}
\hline \multirow[t]{2}{*}{ Tratamento } & \multicolumn{4}{|c|}{ Períodos de avaliação } & \multirow{2}{*}{$\begin{array}{l}\text { Média dos } \\
\text { períodos* }\end{array}$} \\
\hline & $1^{\circ}$ Período & $2^{\circ}$ Período & $3^{\circ}$ Período & $4^{\circ}$ Período & \\
\hline & \multicolumn{5}{|c|}{ CMSD (kg/dia) } \\
\hline $100 \%$ FS & 5,88 & 6,45 & 7,08 & 8,01 & $6,86 \mathrm{~A}$ \\
\hline $66 \% \mathrm{FS}$ & 5,75 & 6,30 & 7,42 & 8,18 & 6,91 A \\
\hline $34 \% \mathrm{FS}$ & 6,01 & 6,67 & 7,62 & 8,23 & $7,14 \mathrm{~A}$ \\
\hline $0 \%$ FS & 5,53 & 6,06 & 6,90 & 7,79 & $6,57 \mathrm{~A}$ \\
\hline \multirow[t]{2}{*}{ Média $^{1}$} & $5,79 \mathrm{~d}$ & $6,37 \mathrm{c}$ & $7,26 \mathrm{~b}$ & 8,06 a & \\
\hline & \multicolumn{5}{|c|}{ CMSP (\% PV) } \\
\hline $100 \%$ FS & 2,35 & 2,15 & 2,08 & 2,10 & $2,17 \mathrm{~A}$ \\
\hline $66 \% \mathrm{FS}$ & 2,29 & 2,10 & 2,15 & 2,11 & $2,16 \mathrm{~A}$ \\
\hline $34 \%$ FS & 2,39 & 2,19 & 2,18 & 2,10 & $2,21 \mathrm{~A}$ \\
\hline $0 \% \mathrm{FS}$ & 2,23 & 2,04 & 2,03 & 2,04 & $2,08 \mathrm{~A}$ \\
\hline \multirow[t]{2}{*}{ Média $^{2}$} & $2,31 \mathrm{a}$ & $2,12 b$ & $2,11 b$ & $2,09 \mathrm{~b}$ & \\
\hline & \multicolumn{5}{|c|}{ CMSM (g/kg $\left.{ }^{0,75}\right)$} \\
\hline $100 \%$ FS & 93,60 & 89,57 & 89,21 & 92,94 & $91,33 \mathrm{~A}$ \\
\hline $66 \%$ FS & 91,27 & 87,51 & 92,65 & 93,56 & $91,25 \mathrm{~A}$ \\
\hline $34 \% \mathrm{FS}$ & 95,06 & 91,35 & 94,37 & 93,50 & $93,57 \mathrm{~A}$ \\
\hline $0 \% \mathrm{FS}$ & 88,37 & 84,82 & 87,03 & 90,19 & $87,60 \mathrm{~A}$ \\
\hline \multirow[t]{2}{*}{ Média $^{3}$} & 92,07 a & 88,31 a & 90,81 a & 92,55 a & \\
\hline & \multicolumn{5}{|c|}{ CPBD (kg/dia) } \\
\hline $100 \%$ FS & 0,934 & 1,024 & 0,858 & 0,822 & $0,910 \mathrm{~A}$ \\
\hline $66 \%$ FS & 0,903 & 0,990 & 0,896 & 0,838 & $0,907 \mathrm{~A}$ \\
\hline $34 \%$ FS & 0,930 & 1,031 & 0,919 & 0,848 & 0,932 A \\
\hline $0 \% \mathrm{FS}$ & 0,857 & 0,940 & 0,827 & 0,794 & $0,855 \mathrm{~A}$ \\
\hline \multirow[t]{2}{*}{ Média $^{4}$} & $0,906 \mathrm{~b}$ & $0,996 \mathrm{a}$ & $0,875 \mathrm{~b}$ & 0,826 c & \\
\hline & \multicolumn{5}{|c|}{ СРBP (\% PV) } \\
\hline $100 \%$ FS & 0,37 & 0,34 & 0,25 & 0,22 & $0,30 \mathrm{~A}$ \\
\hline $66 \%$ FS & 0,36 & 0,33 & 0,26 & 0,22 & 0,29 A \\
\hline $34 \%$ FS & 0,37 & 0,34 & 0,26 & 0,22 & $0,30 \mathrm{~A}$ \\
\hline $0 \% \mathrm{FS}$ & 0,35 & 0,32 & 0,24 & 0,21 & $0,28 \mathrm{~A}$ \\
\hline \multirow[t]{2}{*}{ Média $^{5}$} & $0,36 \mathrm{a}$ & $0,33 \mathrm{~b}$ & $0,25 \mathrm{c}$ & $0,21 \mathrm{~d}$ & \\
\hline & \multicolumn{5}{|c|}{ CPBM $\left(\mathrm{g} / \mathrm{kg}^{0,75}\right)$} \\
\hline $100 \%$ FS & 14,86 & 14,22 & 10,80 & 9,54 & $12,36 \mathrm{~A}$ \\
\hline $66 \%$ FS & 14,34 & 13,75 & 11,19 & 9,58 & $12,21 \mathrm{~A}$ \\
\hline $34 \% \mathrm{FS}$ & 14,69 & 14,13 & 11,37 & 9,63 & $12,46 \mathrm{~A}$ \\
\hline $0 \% \mathrm{FS}$ & 13,70 & 13,15 & 10,44 & 9,19 & $11,62 \mathrm{~A}$ \\
\hline Média $^{6}$ & $14,40 \mathrm{a}$ & $13,81 \mathrm{~b}$ & 10,95 c & $9,48 \mathrm{~d}$ & \\
\hline
\end{tabular}

* Médias seguidas de letras maiúsculas iguais na coluna, para cada variável, não diferem $(\mathrm{P}<0,05)$ pelo teste Tukey.

1. $\mathrm{Y}=4,9547+0,017859 * \mathrm{D}\left(\mathrm{R}^{2}=0,8927 ; \mathrm{CV}=5,13 ; \mathrm{P}<0,0001\right)$, onde $\mathrm{D}=$ dias de confinamento;

2. $\mathrm{Y}=2,3336-0,001585 * \mathrm{D}\left(\mathrm{R}^{2}=0,3078 ; \mathrm{CV}=6,10 ; \mathrm{P}<0,0049\right)$;

3. $\mathrm{Y}=99,3825-0,217625 * \mathrm{D}+0,001039 * \mathrm{D}^{2}\left(\mathrm{R}^{2}=0,1486 ; \mathrm{CV}=5,33 ; \mathrm{P}<0,1846\right)$;

4. $\mathrm{Y}=0,7071+0,006053 * \mathrm{D}-0,000031 * \mathrm{D}^{2}\left(\mathrm{R}^{2}=0,7277 ; \mathrm{CV}=5,02 ; \mathrm{P}<0,0001\right)$;

5. $\mathrm{Y}=0,4206-0,001180 * \mathrm{D}\left(\mathrm{R}^{2}=0,9143 ; \mathrm{CV}=6,66 ; \mathrm{P}<0,0001\right)$;

6. $\mathrm{Y}=16,5457-0,039805^{*} \mathrm{D}\left(\mathrm{R}^{2}=0,8687 ; \mathrm{CV}=6,88 ; \mathrm{P}<0,0001\right)$. 
participação da fração concentrada empregada na dieta alimentar dos bezerros no terceiro e quarto períodos foi suficiente para manutenção da taxa do CMS, seja expressa por porcentagem de peso vivo ou por unidade metabólica, observada no segundo período.

Vários fatores atuam no comportamento de ingestão de alimentos dos ruminantes. MCDONALD et al. (1991) evidenciam que o teor de matéria seca da dieta alimentar atua como um controlador no consumo de alimentos, visto que a água presente nos alimentos resulta em espaço ocupado no trato gastrointestinal. Já EIFERT et al. (2000), trabalhando com bezerros Braford, alimentados com diferentes níveis de concentrado na dieta, verificaram que a elevação dos níveis de concentrado, proporcionou respostas lineares e positivas no CMSP e CMSM, justificando os resultados, entre outros fatores, pela diminuição do tamanho das partículas e a maior densidade física da dieta, que permitiu uma maior taxa de passagem pelo rúmen (OWENS \& GOETSCH, 1993) e pela redução dos teores de FDN da dieta, a qual tem relação negativa com o CMSD em ruminantes (MERTENS, 1992; VAN SOEST, 1994).

Não foram observados efeitos significativos da substituição parcial ou total do FS pelo FSC na dieta alimentar dos bezerros para o CPB expresso nas diferentes formas (Tabela 3). Pode-se observar que a variação de 0 a $100 \%$ de substituição do FS na dieta resultou em consumos similares de proteína bruta, quando expressos em kg/animal (média de 0,901 $\mathrm{kg} \mathrm{dia}^{-1}$ ), por $100 \mathrm{~kg}$ de peso vivo (média de $0,29 \%$ ) e por unidade tamanho metabólico $\left(12,16 \mathrm{~g} \mathrm{~kg}^{-0,75}\right)$.

$\mathrm{Na}$ análise dos períodos de avaliação do confinamento, os CPBD aumentaram $(\mathrm{P}<0,05)$ do primeiro $\left(0,906 \mathrm{~kg} \mathrm{dia}^{-1}\right)$ para o segundo $\left(0,996 \mathrm{~kg} \mathrm{dia}^{-1}\right)$ período, diminuindo no terceiro $\left(0,875 \mathrm{~kg} \mathrm{dia}^{-1}\right)$ e quarto $\left(0,826 \mathrm{~kg} \mathrm{dia}^{-1}\right)$ períodos subseqüentes. Conforme NRC (1984) seriam necessários consumos diários de 0,718 a $0,881 \mathrm{~kg}$ de proteína bruta, respectivamente, para a variação de 200 a $400 \mathrm{~kg}$ de peso vivo, considerando a categoria animal como de elevada composição de ganho, para obtenção de ganhos médios diários de peso na ordem de 1,0kg. Esta comparação respalda os dados contidos na tabela 3 , quando são confrontados com os ganhos de pesos médios diários dos bezerros (Tabela 4). Os maiores CPBD, observados no primeiro e segundo períodos do confinamento, foram resultados diretos da associação dos fatores CMSD e das características da dieta alimentar oferecida aos bezerros com teores médios de PB de 15,6\% para o primeiro e segundo períodos, de $12,1 \%$ para o terceiro e de $10,2 \%$ para o quarto período. Quando o CPB foi expresso por porcentagem do peso vivo e por unidade de tamanho metabólico, estes decresceram $(\mathrm{P}<0,05)$ com o avanço dos períodos do confinamento, apresentando valores médios, respectivamente, de $0,36 \%$ e $14,40 \mathrm{~g} \mathrm{~kg}^{-0,75}$ para o primeiro período, de $0,33 \%$ e $13,81 \mathrm{~g} \mathrm{~kg}^{-0,75}$ para o segundo período, de $0,25 \%$ e $10,95 \mathrm{~g} \mathrm{~kg}^{-0,75}$ para o terceiro período e de $0,21 \%$ e $9,48 \mathrm{~g} \mathrm{~kg}^{-0,75}$ para o quarto período.

Os CED médios (Tabela 4), expressos em kg animal $^{-1}$ (média de 21,54Mcal dia ${ }^{-1}$ ), por porcentagem de peso vivo (média de $6,77 \%$ ) e por unidade de

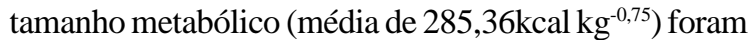
similares $(\mathrm{P}>0,05)$, cujas dietas tiveram substituição parcial ou total do FS pelo FSC. FLORES (1997), avaliando diferentes grupos genéticos de novilhos superprecoce, observou valores variando entre 6,7 e 7,4\% para o CEDP.

Os CEDD aumentaram $(\mathrm{P}<0,05)$ com o avanço dos períodos do confinamento. Do primeiro (17,97Mcal dia $\left.{ }^{-1}\right)$ para o quarto (25,62Mcal dia $\left.{ }^{-1}\right)$ período de avaliação, observou-se aumento no CEDD na ordem de $42,57 \%$. Quando expresso por porcentagem de peso vivo, o CED foi maior $(\mathrm{P}<0,05)$ para o primeiro período (7,20\%) em relação ao segundo (6,60\%), terceiro (6,64\%) e quarto $(6,65 \%)$ períodos subsequentes, justificado pelo maior CMSD. Já quando expresso por unidade de tamanho metabólico, o CED foi maior $(\mathrm{P}<0,05)$ no quarto período de avaliação $\left(294,67 \mathrm{Kcal} \mathrm{kg}^{-0,75}\right)$, não diferindo do primeiro $\left(286,26 \mathrm{Kcal}_{\mathrm{kg}}{ }^{-0,75}\right)$ e terceiro $(285,98 \mathrm{Kcal}$ $\mathrm{kg}^{-0,75}$ ) períodos

A substituição do FS na fração concentrada da dieta dos animais pelo FSC não afetou $(\mathrm{P}>0,05)$ os valores médios do GMD (média de 1,070 $\mathrm{kg} \mathrm{dia}^{-1}$ ) e da CA (média de 6,57 kg de MS kg-1 de PV), como da EPB (média de $0,851 \mathrm{~kg}$ de $\mathrm{PB} \mathrm{kg} \mathrm{kg}^{-1}$ de PV). PASCOAL et al. (2000) avaliando diferentes níveis de proteína bruta na dieta de bezerros Braford, confinados por 84 dias, observaram valores inferiores para o GMD $(0,692 \mathrm{~kg}$ $\left.\mathrm{dia}^{-1}\right)$, no entanto melhor CA (4,21 kg de MS kg ${ }^{-1}$ de PV), frente aos dados obtidos no presente trabalho. Já Restle et al. (1999b), avaliando o desempenho de terneiros Braford em confinamento com relação volumoso: concentrado de 70:30, observaram resultados semelhantes no GMD $\left(1,091 \mathrm{~kg} \mathrm{dia}^{-1}\right)$ e na CA (6,36kg de $\mathrm{MS} \mathrm{kg}^{-1}$ de PV).

Na média geral, os resultados do trabalho foram semelhantes aos relatados por RESTLE et al. (1997) para os parâmetros GMD (1,160kg dia-1) e CA (6,30 $\mathrm{kg}$ de $\mathrm{MS} \mathrm{kg}{ }^{-1}$ de peso vivo) de bezerros Hereford e por Restle et al. (1999b) de bezerros Braford alimentados com baixo e alto nível de concentrado na dieta, com valores médios para o GMD de $1,071 \mathrm{~kg} \mathrm{dia}^{-1} \mathrm{e}$ CA de 6,35.

Na análise dos períodos de confinamento, os GMD dos animais foram semelhantes $(\mathrm{P}>0,05)$ para 
Tabela 4 - Consumo médio diário de energia digestível (CED), expresso em Mcal/animal (CEDD), por $100 \mathrm{~kg}$ de peso vivo (CEDP) e por unidade de peso metabólico (CEDM), ganho de peso médio diário (GMD), conversão alimentar (CA) e eficiência de transformação da proteína bruta (EPB) consumida em ganho de peso de bezerros confinados, de acordo com o tratamento e período de avaliação.

\begin{tabular}{|c|c|c|c|c|c|}
\hline \multirow[t]{2}{*}{ Tratamento } & \multicolumn{4}{|c|}{ Períodos de avaliação } & \multirow{2}{*}{$\begin{array}{l}\text { Média dos } \\
\text { períodos* }\end{array}$} \\
\hline & $1^{\circ}$ Período & $2^{\circ}$ Período & $3^{\circ}$ Período & $4^{\circ}$ Período & \\
\hline & \multicolumn{5}{|c|}{ CEDD (Mcal/dia) } \\
\hline $100 \%$ FS & 18,24 & 20,01 & 22,28 & 25,47 & $21,50 \mathrm{~A}$ \\
\hline $66 \%$ FS & 17,82 & 19,54 & 23,34 & 26,04 & $21,68 \mathrm{~A}$ \\
\hline $34 \%$ FS & 18,65 & 20,68 & 23,97 & 26,19 & 22,37 A \\
\hline $0 \% \mathrm{FS}$ & 17,15 & 18,80 & 21,69 & 24,78 & $20,60 \mathrm{~A}$ \\
\hline \multirow[t]{2}{*}{ Média $^{1}$} & $17,97 \mathrm{~d}$ & $19,76 \mathrm{c}$ & $22,82 \mathrm{~b}$ & $25,62 \mathrm{a}$ & \\
\hline & \multicolumn{5}{|c|}{ CEDP (\% PV) } \\
\hline $100 \%$ FS & 7,32 & 6,69 & 6,54 & 6,70 & $6,81 \mathrm{~A}$ \\
\hline $66 \%$ FS & 7,13 & 6,54 & 6,77 & 6,71 & $6,79 \mathrm{~A}$ \\
\hline $34 \%$ FS & 7,42 & 6,79 & 6,87 & 6,69 & $6,94 \mathrm{~A}$ \\
\hline $0 \% \mathrm{FS}$ & 6,92 & 6,36 & 6,38 & 6,50 & $6,54 \mathrm{~A}$ \\
\hline \multirow[t]{2}{*}{ Média² } & $7,20 \mathrm{a}$ & $6,60 \mathrm{~b}$ & $6,64 \mathrm{~b}$ & $6,65 \mathrm{~b}$ & \\
\hline & \multicolumn{5}{|c|}{ CEDM (kcal/kg $\left.{ }^{0,75}\right)$} \\
\hline $100 \%$ FS & 290,99 & 278,49 & 280,91 & 295,91 & 286,57 A \\
\hline $66 \% \mathrm{FS}$ & 283,76 & 272,06 & 291,77 & 297,90 & 286,37 A \\
\hline $34 \%$ FS & 295,55 & 284,00 & 297,18 & 297,69 & $293,61 \mathrm{~A}$ \\
\hline $0 \% \mathrm{FS}$ & 274,74 & 263,70 & 274,04 & 287,16 & $274,91 \mathrm{~A}$ \\
\hline \multirow[t]{2}{*}{ Média ${ }^{3}$} & $286,26 \mathrm{ab}$ & 274,56 b & $285,98 \mathrm{ab}$ & 294,67 a & \\
\hline & \multicolumn{5}{|c|}{ GMD (kg/dia) } \\
\hline $100 \%$ FS & 1,209 & 1,082 & 0,895 & 0,958 & $1,036 \mathrm{~A}$ \\
\hline $66 \%$ FS & 1,169 & 1,088 & 1,093 & 0,963 & $1,078 \mathrm{~A}$ \\
\hline $34 \%$ FS & 1,392 & 1,020 & 1,076 & 0,956 & $1,111 \mathrm{~A}$ \\
\hline $0 \% \mathrm{FS}$ & 1,143 & 1,077 & 1,029 & 0,967 & $1,054 \mathrm{~A}$ \\
\hline \multirow[t]{2}{*}{ Média $^{4}$} & $1,228 \mathrm{a}$ & $1,067 \mathrm{~b}$ & $1,023 \mathrm{~b}$ & $0,961 \mathrm{~b}$ & \\
\hline & \multicolumn{5}{|c|}{ CA (CMSD/GMD) } \\
\hline $100 \%$ FS & 4,88 & 5,98 & 8,03 & 8,36 & 6,81 A \\
\hline $66 \%$ FS & 4,92 & 5,80 & 6,80 & 8,51 & $6,51 \mathrm{~A}$ \\
\hline $34 \%$ FS & 4,39 & 6,58 & 7,08 & 8,62 & 6,67 A \\
\hline $0 \% \mathrm{FS}$ & 4,84 & 5,64 & 6,72 & 8,06 & 6,31 A \\
\hline \multirow[t]{2}{*}{ Média $^{5}$} & $4,75 d$ & $6,00 \mathrm{c}$ & $7,16 \mathrm{~b}$ & 8,39 a & \\
\hline & \multicolumn{5}{|c|}{ EPB (CPBD/GMD) } \\
\hline $100 \%$ FS & 0,774 & 0,950 & 0,972 & 0,858 & 0,889 A \\
\hline $66 \%$ FS & 0,773 & 0,912 & 0,821 & 0,871 & $0,844 \mathrm{~A}$ \\
\hline $34 \%$ FS & 0,678 & 1,017 & 0,854 & 0,887 & 0,859 A \\
\hline $0 \% \mathrm{FS}$ & 0,750 & 0,874 & 0,807 & 0,821 & 0,813 A \\
\hline Média $^{6}$ & $0,744 \mathrm{~b}$ & 0,938 a & 0,863 a & 0,859 a & \\
\hline
\end{tabular}

* Médias seguidas de letras maiúsculas diferentes na coluna, para cada variável, diferem $(\mathrm{P}<0,05)$ pelo teste Tukey.

1. $\mathrm{Y}=15,0498+0,060651 * \mathrm{D}\left(\mathrm{R}^{2}=0,9011 ; \mathrm{CV}=5,31 ; \mathrm{P}<0,0001\right)$, onde $\mathrm{D}=$ dias de confinamento;

2. $\mathrm{Y}=8,1573-0,027404 * \mathrm{D}+0,000109 * \mathrm{D}^{2}\left(\mathrm{R}^{2}=0,3612 ; \mathrm{CV}=5,68 ; \mathrm{P}<0,0090\right)$;

3. $\mathrm{Y}=311,3208-0,759226 * \mathrm{D}+0,003870 * \mathrm{D}^{2}\left(\mathrm{R}^{2}=0,2510 ; \mathrm{CV}=5,34 ; \mathrm{P}<0,0481\right)$;

${ }^{4} \mathrm{Y}=1,2823-0,001969 * \mathrm{D}\left(\mathrm{R}^{2}=0,5291 ; \mathrm{CV}=9,56 ; \mathrm{P}<0,0001\right)$;

${ }^{5} \mathrm{Y}=3,5609+0,028185 * \mathrm{D}\left(\mathrm{R}^{2}=0,9305 ; \mathrm{CV}=6,74 ; \mathrm{P}<0,0001\right)$

${ }^{6} \mathrm{Y}=0,4137+0,009566 * \mathrm{D}-0,000041 * \mathrm{D}^{2}\left(\mathrm{R}^{2}=0,6341 ; \mathrm{CV}=7,65 ; \mathrm{P}<0,0001\right)$. 
o segundo $\left(1,067 \mathrm{~kg} \mathrm{dia}^{-1}\right)$, terceiro $\left(1,023 \mathrm{~kg} \mathrm{dia}^{-1}\right)$ e quarto períodos $\left(0,961 \mathrm{~kg} \mathrm{dia}^{-1}\right)$, diferindo $(\mathrm{P}<0,05)$, no entanto do primeiro período de confinamento, $(1,228 \mathrm{~kg}$ $\left.\mathrm{dia}^{-1}\right)$. Os maiores GMD dos animais, no primeiro período do confinamento, podem ser atribuídos à maior CMS (Tabela 3). No avanço do primeiro (4,75kg de $\mathrm{MS} \mathrm{kg}^{-1}$ de PV), para o segundo (6,00kg de $\mathrm{MS} \mathrm{kg}^{-1}$ de PV), terceiro $\left(7,16 \mathrm{~kg}\right.$ de $M S \mathrm{~kg}^{-1}$ de PV) e quarto $\left(8,39 \mathrm{~kg}^{\mathrm{de}}\right.$ MS kg-1 de PV) período do confinamento dos animais houve redução significativa da CA, respectivamente. Devido ao maior CMSP (Tabela 3) observado no primeiro período, a EPB $\left(0,744 \mathrm{~kg}\right.$ de $\mathrm{PB} \mathrm{kg}^{-1}$ de peso vivo) foi melhor $(\mathrm{P}<0,05)$ frente aos demais períodos avaliados.

\section{CONCLUSÕES}

Não há diferença no consumo de alimentos e no desempenho de bezerros de corte terminados em confinamento com diferentes níveis de substituição do farelo de soja pelo farelo de soja centrifugado na fração concentrada da dieta alimentar. O farelo de soja centrifugado pode ser utilizado sem restrições como fonte protéica substitutiva ao farelo de soja na dieta de terneiros da raça Braford terminados aos 14 meses em confinamento.

\section{AGRADECIMENTOS}

Ao Conselho Nacional de Desenvolvimento Científico e Tecnológico (CNPq), pela concessão da bolsa ao pesquisador Souza.

\section{REFERÊNCIAS}

AGRICULTURAL RESEARCH COUNCIL - ARC. The nutrients requirements of ruminants livestock. London: Technical review by on Agricultural Research Council working Party, 1980. 351p.

ASSOCIATION OF OFFICIAL ANALYTICAL CHEMISTS AOAC. Official methods of analysis. 14.ed. Washington, D.C., 1984. 1141p.

BRITO, R.M. et al. Efeito de fontes protéicas associadas à silagem de milho no crescimento de bezerros mestiços canchim confinados pós-desmama. In: REUNIÃO ANUAL DA SOCIEDADE BRASILEIRA DE ZOOTECNIA, 34., 1997, Juiz de Fora. Anais... Juiz de Fora: SBZ, 1997. p.292-294.

EIFERT, E.C. et al. Desempenho de terneiros de corte desmamados precocemente alimentados com silagem de sorgo associada a diferentes níveis de concentrado. In: REUNIÃO ANUAL DA SOCIEDADE BRASILEIRA DE ZOOTECNIA, 37., 2000, Viçosa. Anais... São Paulo: SBZ/Gmosis, [2000] 17par. CD-ROM.
FLORES, J.L.C. Desempenho em confinamento de terneiros inteiros de diferentes grupos genéticos na fase do desmame ao abate aos quatorze meses. 1997. 136f. Dissertação (Mestrado em Zootecnia) - Universidade Federal de Santa Maria.

McDONALD, P. et al. The biochemistry of silage. 2.ed. Toronto: Chalcombe publications, 1991. 339p.

MERTENS, D.R. Análise de fibra e sua utilização na avaliação de alimentos e formulação de rações. In: SIMPÓSIO INTERNACIONAL DE RUMINANTES, REUNIÃO ANUAL DA SOCIEDADE BRASILEIRA DE ZOOTECNIA, 29., 1992, Lavras. Anais... Lavras: SBZ, 1992. p.188-219.

NATIONAL RESEARCH COUNCIL - NRC. Nutrient requirements of domestic animals. Washington, DC.: National Academy of Sciences, 1984. 90p.

OWENS, F.N.; GOETSCH, A.L. Fermentación ruminal. In: CHURCH, D.C. (Ed). El ruminante, fisiología digestiva y nutrición. Zaragoza, España: Acríbia, 1993. p.159-190.

PASCOAL, L.L. et al. Nível de proteína bruta para bezerros de corte desmamados aos 66 dias de idade. Revista Brasileira de Zootecnia, v.29, n.5, p.1537-1544, 2000.

PELEGRINI, L.F.V. et al. Fontes protéicas sobre o desempenho de terneiros confinados. Ciência Rural. v.30, n.3, p.475-479, 2000.

RESTLE, J. et al. Desempenho em confinamento, do desmame ao abate aos quatorze meses, de bovinos inteiros ou castrados, produzidos por vacas de dois anos. Ciência Rural, v.27, n.4, p.651-655, 1997.

RESTLE, J. et al. O novilho superprecoce. In: RESTLE, J. Confinamento, pastagens e suplementação para produção de bovinos de corte. Santa Maria: UFSM, 1999a. p.191-214.

RESTLE, J. et al. Produção de terneiros para abate aos 12 meses, alimentados com silagens de milho colhida a duas alturas de corte, associadas a dois níveis de concentrado. In: REUNIÃO ANUAL DA SOCIEDADE BRASILEIRA DE ZOOTECNIA, 36, 1999b, Porto Alegre. Anais... São Paulo: SBZ/Gmosis, [1999b] 17par. CD-ROM.

RESTLE, J. et al. Eficiência na terminação de bovinos de corte. In: RESTLE, J. (Ed). Eficiência na produção de bovinos de corte. Santa Maria: UFSM, 2000. p.277-303.

SAS INSTITUTE. SAS/STAT user's guide: statistics. Version 6. 4.ed. Cary, NC, 1993. V.2. 943p.

TILLEY, J.M.A.; TERRY, R.A. A two-stage technique for the in vitro digestion of forage crop. Journal British Grassland Society, v.18, n.2, p.104-111, 1963.

VAN SOEST, P.J.; WINE, R.H. Use of detergents in analysis of fibrous feeds. IV. Determinations of plant cell-wall constituents. Journal of Association Official Analysis Chemists, v.50, p.50, 1967.

VAN SOEST, P.J. Nutritional ecology of the ruminant. 2.ed. Ithaca: Cornel University, 1994. 476p. 